\title{
O CAMPO CIENTÍFICO DE BOURDIEU E O PESQUISADOR QUÍMICO
}

\section{ENSAIO TEÓRICO}

FIORI, Raquel ${ }^{1}$

FIORI, Raquel. O campo científico de Bourdieu e o pesquisador químico. Revista Científica Multidisciplinar Núcleo do Conhecimento. Ano 05, Ed. 05, Vol. 12, pp. 118127. Maio de 2020. ISSN: 2448-0959, Link de acesso: https://www.nucleodoconhecimento.com.br/quimica/pesquisador-quimico

\section{RESUMO}

Bourdieu propõe uma leitura sobre a conduta do ser humano objetivando compreender as causas e as consequências das ações dos mesmos, com intuito de controlar ou induzir comportamentos que possam favorecer a sociedade. Ele adota uma perspectiva abrangente de grandes grupos sociais tomados em conjunto para interpretar as práticas sociais das ações dos indivíduos. Neste contexto, a problemática aqui exposta explora o pesquisador químico no seu campo científico, discutindo a relação entre este agente social em seu capital puro e ou institucional que vem de encontro as suas motivações e obrigações perante o espaço social. É precisamente esse espaço inserido no campo cientifico que constitui o foco deste artigo, a partir do estudo das relações do pesquisador químico como um ator social que busca responder a aplicabilidade deste conceito nas ações dos profissionais químicos em seu meio: compreender como se processa e quais as características que interferem e contribuem para a construção do ser químico perante a ciência de Bourdieu. A metodologia adotada é a pesquisa bibliográfica e descritiva, abrangendo literaturas pertinentes sobre o tema em questão. Os resultados foram analisados sob a ótica das contribuições teóricas sobre a teoria de Campo Cientifico de Pierre

1 Doutoranda em Educação em Ciências (UFRGS). Mestrado em Ciências e Tecnologia de Alimentos (UFRGS). Pós-graduação em Ciências e Tecnologia de Alimentos (UFRGS). Graduação em Química Bacharelado e Tecnológico (PUC RS). 
Bourdieu. Concluindo que o profissional de química, deve entender a lógica do jogo no seu espaço social de concorrência cientifica.

Palavras-chave: Bourdieu, campo científico, pesquisador químico.

\section{INTRODUÇÃO}

\subsection{BOURDIEU}

Pierre Bourdieu, sociólogo francês criou a percepção de campo científico em seu livro "Os usos sociais da ciência: por uma sociologia clínica do campo científico", para explicar as relações de poder nas pretensões científicas.

Conforme cita Bourdieu (1983a) tal campo constitui-se em uma estrutura em que agentes ocupam posições a partir do acúmulo de capital científico adquirido ao longo de sua trajetória acadêmica por meio de lutas para alcançar o melhor lugar nessa estrutura. Tornando-se, portanto, uma forma de cooperação ou de rivalidade entre cientistas em suas diferentes atividades e Instituições.

Bourdieu (2007) elabora alguns conceitos como a teoria do habitus e do campo, e os tipos de capital que elucidam a caracterizar a conduta social.

O conceito da teoria de habitus desenvolvido por Bourdieu ficou definido como um "sistema de disposições (mecanismo de ação) duráveis e transponíveis que, integrando todas as experiências passadas, funcionam como uma matriz de percepções, de apreciações e de ações" (BOURDIEU, 1983a, p.65).

Para as três categorias de capital, define-se capital social como uma rede de relações, já o capital simbólico tem relação com a influência e deferência do agente. O capital cultural possui uma estrutura de apropriação/desapropriação.

Ainda, o conceito de campo trata de um enfrentamento de forças entre os indivíduos relacionados e suas instituições, podendo existir diversos campos, como o político, econômico, acadêmico, esportivo, artístico, etc. 
Reunindo estes conceitos, Bourdieu (2007) entende que a prática social de um indivíduo pode ser compreendida como de uma ligação a um campo, em função da relação habitus e capital.

O confronto de domínios da capacidade científica e influência social, marca a conformação dos profissionais, neste caso, os químicos, dentro do "campo" que define o que eles podem ou não fazer (Figura1).

Figura 1 - Ocupação de posições no campo científico

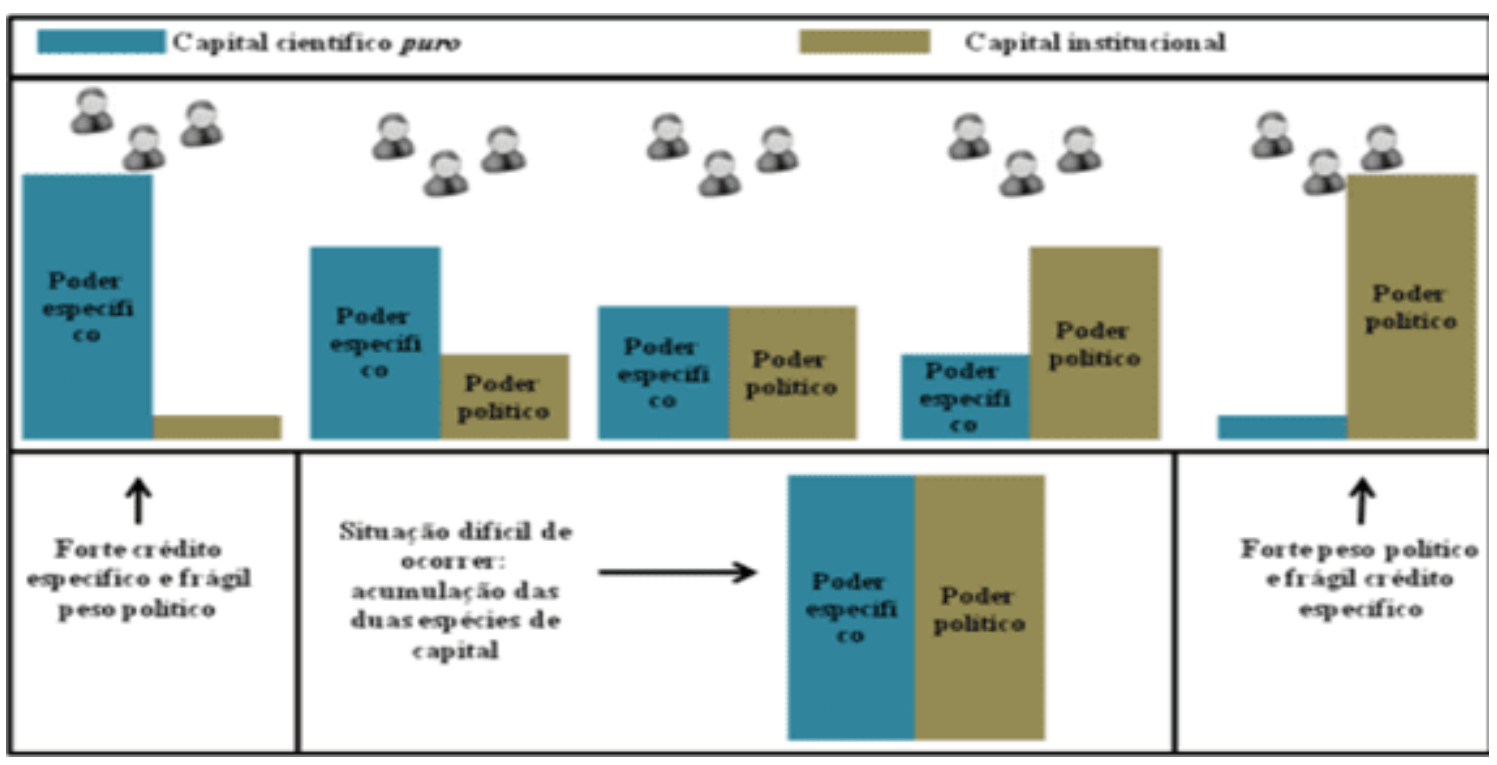

Fonte: Teixeira, 2011, pag.63

Os vários interesses dos profissionais estão claros no campo científico do qual são produzidos pelos mesmos. Portanto, a todo instante há um julgamentos sobre a atividade científica de um estudante ou de um pesquisador ao longo de sua trajetória profissional ou acadêmica, pela posição que ele ocupa em suas instituições, dificultando assim que haja a inserção no mercado de trabalho.

Aplicando a definição de capital puro e institucional, o "ser" químico encontra-se forte ante as pressões sociais que atacam continuamente o campo e assim liberta - se para uma posição adequada dentro do seu universo de trabalho. 
Aplica-se o conceito de campo científico na área de química para que se possa modificar as práticas pela busca de estratégias políticas de investimento orientada para o lucro propriamente científico, isto é, a conquista do mérito em detrimento do desenvolvimento do talento científico e de novas descobertas úteis à sociedade.

Este trabalho procura identificar o pesquisador químico como um ator social (representante de algo para a sociedade) no seu campo científico, buscando responder a aplicabilidade deste conceito (de campo científico) nas ações do profissional químico em seu meio, seja indústria, laboratório de pesquisa ou análise e ensino, tanto da rede pública como privada. Esclarecendo como o "ser" químico situase perante a ciência de Bourdieu, quais suas motivações e obrigações neste campo desde sua carreira acadêmica por meio de dificuldades de engajamento e confrontos entre os seus pares para alcançarem a posição mais adequada em sua categoria.

Como veracidade da relação dos conceitos de Bourdieu com os profissionais de química lança-se a seguinte hipótese (tabela 1):

Tabela 1- Hipóteses dos profissionais químicos x conceitos de Bourdieu

\begin{tabular}{|l|l|}
\hline Conceito de Bourdieu & Profissional de Química \\
\hline Campo Científico & depende da formação do químico e \\
\hline Capital Puro & definidor da área de atuação \\
\hline Capital Institucional & talento natural do químico e formação \\
\hline Espaço Social & acadêmica \\
\hline
\end{tabular}

Fonte: Elaboração própria 


\subsection{TEORIA BOURDIEUSIANA}

$\mathrm{Na}$ teoria bourdieusiana, por processo de reconstrução racional do conhecimento científico, dos desdobramentos e dedução, chega-se a compreender a prática ou as práticas pela reflexão sobre a ação, o objetivismo e a fenomenologia, destacando-se os aspectos da experiência humana no sistema de relações objetivas.

Em sua teoria Bourdieu exemplifica a rotina social de indivíduos em suas corporações ou em suas individualidades que buscam resgatar o declínio coletivo de classe (BOURDIEU, 1979). As mudanças na estratégia levam a constante adaptação das organizações contemporâneas. As estratégias fariam parte de uma dinâmica social ligada à mudança nos patrimônios ou capitais de grupos e à possibilidade de conversão de um tipo de capital em outro, o que Bourdieu denomina "estratégias de reconversão" (BOURDIEU, 1979).

Há entre os pesquisadores de poder, certo entendimento da mobilidade que podem operar no curso de suas vidas quando do acúmulo de recursos e capital.

Para Bourdieu (2012), há duas estratégias de reconversão, a primeira são as verticais, isto é, ela se dá entre os pesquisadores situados dentro de um mesmo campo.

Esses pesquisadores se movimentam em sentido vertical dentro de um mesmo campo, orientado pelas especificidades, e sua característica principal está no simples acúmulo de capital e recursos concernentes àquele campo.

Há outra estratégia de reconversão, menos comum, que são as transversais. Essa estratégia consiste em se deslocar de um determinado campo para outro.

A estratégia de reconversão transversal é muito efetuada quando o pesquisador já detém relativo capital e recursos dentro de seu campo de origem.

Os químicos enquadram-se na teoria bourdieusiana com suas estruturas de relações objetivas entre os pesquisadores químicos, isto é, suas posições dentro do "campo", 
suas posturas e capacidades de prever as ações presentes de forma a resgatar os lucros no futuro.

Neste contexto, o campo cumpre uma função de mediação, no qual nele estão os químicos e as instituições que possuem suas próprias leis, quanto mais favorecida é a posição deste pesquisador no campo, mais ele trabalhará para conservar a estrutura e a sua posição.

Desse modo, os químicos são dotados de um capital situado em seu campo científico próprio, que eles experimentam no decorrer de sua carreia científica.

Nesse caso, o laboratório (campo ou subcampo de um químico) tem uma posição peculiar na estrutura disciplinar e dispõe de autonomia para ser um espaço de produção do conhecimento e da produção dos capitais científicos e administrativos (BOURDIEU, 2001).

A vida científica de um ser químico é difícil. Os pesquisadores estão expostos a sofrer e inventam estratégias individuais destinadas a atenuar o sofrimento, pois as ciências de laboratório têm possivelmente mais tendência a provocar o isolamento social.

Em uma sólida formação acadêmica para um químico se compara a teoria do capital puro adquirido pelas participações desenvolvidas em prol do progresso das ciências: invenções ou as descobertas.

Bourdieu menciona que é mais fácil metamorfosear o capital puro em institucional, pois este é adquirido pelo estabelecimento de relações políticas.

Estas hierarquias dos elementos práticos da realidade, evidenciadas como diferenças salariais, duração de formação, investimentos financeiros necessários para obtenção de títulos permitem ao químico no exercício de sua profissão, que privilegiem as dinâmicas colaborativas, com o preparo para o exercício da cidadania e sua qualificação direcionada aos interesses comuns da população atingida pelos projetos desenvolvidos por estes profissionais. 


\subsection{CULTURA PROFISSIONAL E A COMUNIDADE DOS QUÍMICOS}

A relação entre a ciência e as questões de produção e desenvolvimento econômico começou com o capitalismo, tornando a ciência a propulsora do período industrial.

As diversas instituições criadas no período colonial foram essenciais para a divulgação da Química, com a finalidade prática ou integrada como disciplina básica de alguns currículos. As análises sobre minerais, drogas farmacêuticas, solo, manufatura do açúcar, extração de substâncias salinas, dentre outras, corroboraram para a produção de compêndios químicos para os estudos da prática química em território brasileiro.

O que se consegue constatar e perceber, em decorrência dessa associação da prática com a teoria, é que houve um grande avanço para novas técnicas de análise e síntese química.

Estas últimas consistem na identificação qualitativa e quantitativa das espécies químicas procurando explicar as transformações em novos produtos, daí o surgimento de curas de doenças, da tecnologia e outros.

O reconhecimento da importância da ciência passava por aspectos de valorização não só da ciência prática e aplicada, mas também da ciência pura, que servia de base para a primeira.

O químico alemão Justus von Liebig (MAAR,2006), observou que os trabalhos de natureza prática despertava mais a atenção e infundiam mais respeito do que os puramente científicos.

A atuação do profissional químico começa em um laboratório, mas a demanda para outras instalações como nas indústrias, nas linhas de produção, controle de qualidade, nas áreas de planejamento e direção das empresas também é muito requisitada. Podendo atuar também nas instituições de ensino e instituto de pesquisas. 
Observa-se que caberá ao químico dirigir-se ao campo mais adequado dentro de sua carreira, assim, configura-se que o "ser" químico deverá ter uma porção de capital puro para que se tenha maior independência em relação aos reveses do campo e do espaço social.

Ao salientar a importância dos recursos humanos em química, é fundamental destacar a pesquisa, as relações interinstitucionais, a formação, os desafios, as transformações recentes ocorridas no desenvolvimento do setor. Quando se trata do profissional do futuro, deve-se dar ênfase a situação em que o mercado dita o que deve ou não ser objeto de pesquisa e, além disso, dita qual deve ser o ritmo das atividades do setor.

O ponto essencial que permeia as discussões é a maneira de "fazer" química para a do "criar" nas áreas de produção científica e atividades de pesquisa.

As dificuldades de absorção do químico pelo mercado de trabalho apesar do crescente número de mestres e doutores faz com que os mesmos sejam direcionados ao campo academia.

Em busca de ações mais concretas, é necessário ter a concepção do quão fundamental é gerar no estudante a vontade do "ser" químico com a introdução de novas tecnologias no ensino médio tornando-as mais familiares aos alunos para que cheguem mais preparados no ensino superior com a introdução da inovação e da criatividade.

A dificuldade do qual temos vivenciado nestes últimos anos, sobre ter aporte financeiro para as pesquisas vem ameaçando a evolução da ciência no país. Os constantes cortes profundos no orçamento destinado para a Ciência \& Tecnologia fez com que as agências de fomento despencassem seus aportes nos editais, ficando sem recursos até para custear projetos aprovados (ENAGO ACADEMY, 2019).

O contingenciamento de recursos afeta a produção de conhecimento tornando a situação mais precária, podendo fazer com que haja a perda de uma geração de cientistas químicos, devido a esta falta de recomposição orçamentária, pois os cientistas precisam de suporte para dedicar seu tempo à investigação. 
O maior desafio de um pesquisador é gostar do que faz, assim haverá motivação para qualificação constante. Não são apenas os recursos financeiros que envolvem um bom profissional a um estudo continuado e sim saber que progresso positivo em que a ciência se encontra pode oferecer ao país e aos seus cidadãos benefícios de uso. Ideias originais necessitam da essência da qualidade da pesquisa em oferta nas Instituições com apoio, com politicas sustentáveis e fomentos duradouros. Do contrário, a acomodação pode fazer com que o pesquisador emigre para países com tradição nesse segmento. Ainda o pesquisador sofre preconceito contra a ciência praticada em nosso país, alguns trabalhos são vistos com restrição, apesar de a pesquisa ser de interesse.

Apesar de cientistas brilhantes, mas por não conseguirem transformar seu conhecimento em benefícios, ocorrem em muitos casos, frustração e desistência.

A cultura da academia é um campo de forças (BOURDIEU, 2007), focada em Ego, através da alta competitividade, anseio pelo prestigio e acima de tudo comoção e dedicação.

Não é surpreendente observar que nas comunidades dos químicos a verticalização de atribuições deva ser reestruturada, este novo modelo de gestão de pessoas traz uma etapa evolucionária a estes profissionais a fim de potencializar as oportunidades para os inúmeros profissionais em diferentes áreas da química.

A cultura profissional do pesquisador químico deve estar focada no desenvolvimento da ciência e da inovação tecnológica para que se explore e avance as fronteiras do conhecimento em prol do progresso para o país e em apoio à sociedade.

\section{CONSIDERAÇÕES FINAIS}

Segundo Bourdieu (1983b) o campo, e também o campo científico, se explica entre outras coisas através da definição de objetos de disputas e dos interesses específicos que são irredutíveis aos objetos de disputas e aos interesses próprios de outros 
campos, ou seja, no final quanto mais favorecida é aposição de um químico no campo, mais ele vai trabalhar para conservar a estrutura e sua posição.

O campo de Bourdieu e o pesquisador químico precisam estar livres das forças que o atacam continuamente no campo e consequentemente conseguir uma posição confortável dentro do seu universo e para tal, este "ser" químico precisa desenvolver deste cedo o seu capital puro e após fortalecer um volume considerável do capital institucional, pois o espaço social é uma representação multidimensional da estrutura da sociedade.

Portanto, o pesquisador químico possui um significativo capital que está relacionado ao prestigio pessoal, sucesso na atividade e descoberta cientifica que contribui para o campo social do qual está inserido junto aos seus pares.

\section{REFERÊNCIAS}

BOURDIEU, Pierre. La distinction. Paris: Les Éditions de Minuit, 1979.

BOURDIEU, P. Esboço de uma teoria da prática. In: ORTIZ, R. (Ed.) Pierre Bourdieu: Sociologia. São Paulo: Ática, 1983 a.

BOURDIEU, P. Algumas propriedades do campo. Questões de Sociologia. Rio de janeiro: Marco Zero,1983b.

BOURDIEU, Meditações pascalianas. Rio de Janeiro: Bertrand Brasil, 2001.

BOURDIEU, P. A economia das trocas simbólicas (5a ed.). São Paulo: Perspectiva. 2007.

BOURDIEU, P.; PASSERON, J-C. Les héritiers: les étudiants et la culture. Paris: Les Éditions de minuit, 2012.

ENAGO ACADEMY, Como se tornar um bom pesquisador. Disponível em: < http://www.enago.com.br/blog/como-se-tornar-um-bom-pesquisador/> Acesso em 06 de maio de 2019. 
MAAR, J. Justus Von Liebig, 1803-1873. Parte 1: vida, personalidade, pensamento. Quím. Nova [online].vol.29, n.5, pp.1129-1137. ISSN 0100-4042. 2006.

TEIXEIRA, Juliana Cristina. Dinâmica do campo científico e os capitais em jogo na pesquisa em uma universidade pública. Dissertação (Mestrado em Administração) - Universidade Federal de Lavras, Lavras, 198p, 2011.

Enviado: Março, 2020.

Aprovado: Maio, 2020. 